experts in environmental sciences had been in control.

Vogel does not pronounce judgement on the relative merits of the two systems of control. The American system is more time-consuming and expensive in legal costs. The British system relies on flexibility which can become mere laxity. Perhaps the secret of a successful policy is to be inflexible over principles (for example over the environmental quality standard ultimately desired) but flexible in the manner and pace at which one proceeds toward the desirable goal. Doubtless, on the statute book, the United States has the best-protected environment in the world; but the words of the statute book have not reached many of the rivers nor much of the atmosphere. The British statute book is more modest in its aspirations for the environment; but it does not often prescribe what could not be enforced without constant applications to the courts. Transferred to Vogel's larger canvas, this shows an interesting and (I suspect) controversial picture. Are the mild British regulations, the preference for self-disciplined industry, signs of weakness in Westminster, or of a strong and respected government which can afford to rely on voluntary compliance? And is the American "reliance on ruleoriented enforcement" a sign that Washington can bring to heel unsocial behaviour in industry, or is it a sign of weakness in a government which does not command the loyalty of its industrial corporations?

It is no mere academic exercise to reflect on these questions. Expand Vogel's theme from environmental control to the control of trade-unions, corporationcartels and local government, and you see its significance. Upon the answers to these questions depend the patterns of government Britain and the United States will have in the twenty-first century.

Lord Ashby is a Fellow of Clare College, Cambridge CB2 1TL, UK. He was Chairman of the Royal Commission on Environmental Pollution from 1970 to 1973, and sometime member of the House of Lords Select Committee which deals with environmental directives from the European Economic Community.

\section{Fuss over nothing}

\section{W.D. Hackmann}

Leviathan and the Air-Pump: Hobbes, Boyle, and the Experimental Life. By Steven Shapin and Simon Schaffer. Princeton University Press:1986. Pp.440. $\$ 60, £ 43$.

THE air-pump, more than any other scientific instrument, was the emblem of the revolution in physics that took place in the mid-seventeenth century. Other devices, such as the telescope, microscope, thermometer and barometer, preceded it, and all of them had a dramatic impact on how scientists conducted research and viewed the world. But the air-pump was the first mechanical device which made it possible for experiments to be carried out in a controlled laboratory environment - in this case, inside a glass bell-jar. It was also the seventeenth-century equivalent of "Big Science": very expensive, difficult to manufacture and temperamental to operate. Only a handful were made and each one was a prototype. The pump did become commercially available in the late $1670 \mathrm{~s}$, but it remained a costly instrument affordable only by wealthy virtuosi.

Until the middle of the seventeenth century, vacuum experiments were done in the small space above the mercury in the Torricellian barometer tube. Then, in about 1654, Otto von Guericke captured the public imagination with a startling performance of his "Magdeburg hemispheres"; two teams of burly horses could not pull the hemispheres apart after the air within them had been exhausted by the first mechanical air-pump ever constructed. Robert Boyle's interest was aroused after reading about von Guericke's device in a book published in 1659 , by the Jesuit Kaspar Schott, a prolific writer on scientific subjects. Boyle, and his assistant Robert Hooke, immediately set to work to develop a better pump. More significantly, Boyle began an experimental programme to delineate the properties of the vacuum inside the bell-jar of his pump. The results and conclusions were published in New Experiments PhysicoMechanical Touching the Spring of Air $(1660)$, where Boyle consolidated his ideas about what he considered to be the proper experimental method (upon which much of our present-day science is based). New Experiments... touched off a series of controversies in the $1660 \mathrm{~s}$ and $1670 \mathrm{~s}$ that went far beyond what we would conventionally consider to be the realms of science. It is these controversies that are the subject of Shapin and Schaffer's impressive book.

The chief protagonists were Boyle and the philosopher Thomas Hobbes, onetime mathematics tutor to Prince Charles (Charles II). While Hobbes became best known for his political philosophy, expressed in Leviathan (1651), he also took a deep interest in science. The fullest statement of his philosophy of science is to be found in Dialogus physicus (1661), written in response to Boyle's experiments on the spring of air and here appearing for the first time in English translation.

Boyle distinguished between "obvious experiments" - simple observations of naturally occurring phenomena - and "unobvious" or "elaborate experiments" in which artificial phenomena were produced by apparatus, in this case the air-pump. The difficulties faced by Boyle are not unfamiliar to the modern experimental scientist: problems with the physical integrity of his pump (leakage, for example), with standardizing or calibrating the phenomena, and with replication. All these matters led to disputes with his fellow scientists but, as Shapin and Schaffer demonstrate, the confrontation with Hobbes was much more profound and went to the heart of the experimental method. For Hobbes not only rejected the

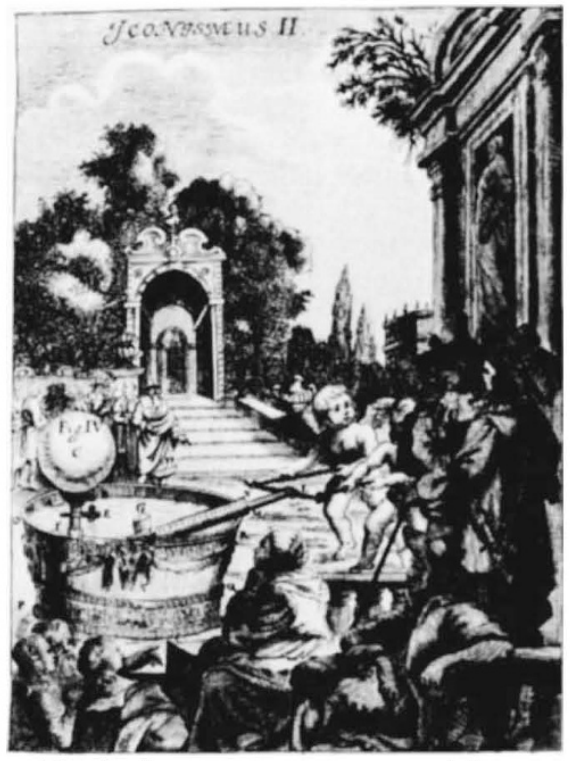

Public display - a demonstration of Otto von Guericke's air-pump in Germany, in the mid seventeenth century, reproduced from Technica curiosa sive mirabilia artis (1687).

existence of the vacuum in nature but (to borrow from Wittgenstein) he played a different "language-game", arguing that only reason or philosophy, not Boyle's "engine philosophy", could yield reliable knowledge.

According to Shapin and Schaffer, this controversy was not so much about science as about social order. They examine the social conventions established for producing knowledge, and Boyle's techniques for making his experimental results acceptable to the scientific community. Thus (as the authors put it), the book is an exercise in the "sociology of scientific knowledge" and is written primarily for the community of scientific historians. Scientists may find this community's particular language-game at times rather off-putting, with its terms such as "literary technology" and "boundary-speech", and they will not find out how Boyle discovered the gas law (for which his air-pump was not necessary). But they should gain some thought-provoking insights into the complex relationship between experiment, theory, and the political and intellectual community.

W.D. Hackmann is Assistant Curator at the Museum of the History of Science, University of Oxford, Broad Street, Oxford OXI $3 A Z$, UK. 